\title{
The Effect of a Novel Training Program to Improve Trunk Stability Push Up Performance in Active Females: A Pilot Study
}

\author{
Kate Schwartzkopf-Phifer ${ }^{1}$ (D) ${ }^{\text {, }}$, Suzanne Leach ${ }^{2}$, Katie Whetstone ${ }^{1}$, Kevin Brown ${ }^{3}$, Kyle Matsel ${ }^{1}$ \\ ${ }^{1}$ Department of Physical Therapy, University of Evansville, ${ }^{2}$ Rehabilitation and Performance Institute, PSC, ${ }^{3}$ Rehabilitation and Performance Institute \\ Keywords: females, trunk stability, functional movement \\ https://doi.org/10.26603/001c.28055
}

\section{International Journal of Sports Physical Therapy}

Vol. 16, Issue 5, 2021

\section{Background}

Trunk stability is a risk factor commonly associated with lower extremity injuries, particularly in females. Performance on trunk stability tasks, such as the Trunk Stability Push Up (TSPU), is less than optimal in females. Current corrective programs include few females, and clinically, improvements for females have been minimal.

\section{Purpose/Hypothesis}

The purpose of this pilot study was to determine the effectiveness of a novel trunk stability intervention program in improving TSPU performance in a cohort of active female participants. It was hypothesized that $\geqslant 60 \%$ of participants would improve their TSPU scores to $\geqslant 2$ via Functional Movement Screen ${ }^{\mathrm{TM}}\left(\mathrm{FMS}^{\mathrm{TM}}\right)$ criteria following a novel six-week intervention program.

\section{Study Design}

Pilot Cohort Study

\section{Methods}

Participants were screened for pain with lumbar and shoulder clearing tests and hypermobility was assessed using Beighton scores. Additional testing included a breathing screen, the FMS ${ }^{\mathrm{TM}}$, Y-Balance Test-Lower Quarter and Y-Balance Test-Upper Quarter. Participants who scored a 1 on the TSPU received a home exercise program instructed by student physical therapists. Exercises focused on improving awareness of lumbar spine position and thoracic spine mobility. Participants returned for follow-ups after two and four weeks for instruction in exercise progression, which increased postural demand on the lumbar spine and upper extremities, and utilized closed-chain, multiplanar stability strategies.

\section{Results}

Nine of 20 participants (45\%) scored $\geqslant 2$ on the TSPU at posttest. Due to the COVID-19 pandemic, only 12 participants were able to complete all posttest outcome measures. No significant differences were noted in the remaining outcome measures.

Conclusion: The results of this study indicate that a multiplanar exercise approach, combining anti-extension and anti-rotation training, was beneficial for inducing trunk stability improvements in some active females.

\footnotetext{
Corresponding Author: 


\section{Level of Evidence}

$2 \mathrm{~b}$

\section{INTRODUCTION}

The susceptibility of the lower extremity (LE) to musculoskeletal injury in sports can vary based on biological sex differences. ${ }^{1,2}$ LE injuries in active adults can occur in either sex, however, females tend to have higher injury incidences compared to their male counterparts. When compared to male counterparts, female collegiate and high school athletes are greater than two times more likely to sustain an anterior cruciate ligament (ACL) injury. ${ }^{3}$ Additionally, LE stress fracture rates in high school female athletes outpace rates in males by nearly two-fold. ${ }^{4}$ Likewise, the prevalence of chronic low back pain is $50 \%$ higher in females over the age of 18 relative to males. ${ }^{5}$ The impact of LE injuries in active females has significant financial implications directly related to health care utilization and costs. Specifically, females aged 15-44 with LE injuries accounted for more than 590,000 visits to the emergency department in 2010 , with an average cost of over $\$ 1,700$ per visit. $^{6}$

Several risk factors have been identified to explain the disproportionate LE injury rates, such as altered neuromuscular control and landing mechanics at the knee, 7,8 anatomic differences, ${ }^{9}$ and impaired postural ${ }^{9,10}$ and trunk stability. ${ }^{11}$ Though trunk stability is an important risk factor to address in females, it is inherently difficult to measure; no standardized definition of trunk stability currently exists, therefore, no standard measurement exists. Examples of trunk stability measures include isometric strength tests of the trunk and hip, ${ }^{11,12}$ trunk endurance holds, ${ }^{13}$ and planking or bridging activities. ${ }^{14}$ Due to the variability in testing methodology, it may be more practical to utilize a measurement that captures all these factors simultaneously.

One test which has been theorized to measure core function is the Trunk Stability Push Up (TSPU). ${ }^{15,16}$ The TSPU is a component of the Functional Movement Screen ${ }^{\mathrm{TM}}$ (FMS $^{\mathrm{TM}}$ ) which consists of seven fundamental movement patterns designed to quickly screen for major movement limitations and pain. ${ }^{17}$ Multiple authors have reported that poor performance on the $\mathrm{FMS}^{\mathrm{TM}}$ is associated with increased injury risk in active male and female populations. ${ }^{18-20}$ Specifically, the scoring of the TSPU test demonstrates excellent inter-rater reliability $(k w=0.82)$ and fair to good intra-rater reliability $(k=0.68) .{ }^{21}$ Furthermore, the TSPU can be easily administered in any setting without additional equipment requirements. Thus, the TSPU may be a functional, field-expedient alternative to capture the construct of trunk stability.

In adolescents, a significant difference $(p=0.000)$ in TSPU performance was noted by Abraham et al, with males outperforming females. ${ }^{22}$ Anderson et al reported 69\% ( $\mathrm{n}=20 /$ 29 ) of high school females failed the TSPU (defined as scoring a 1 using the FMS ${ }^{\mathrm{TM}}$ scoring criteria) compared to only $13 \%(n=4 / 31)$ of males. ${ }^{23}$ This gender difference has been observed in collegiate athletes as well, with females scoring significantly lower than males $(\mathrm{p}<0.001) .{ }^{24}$ The gender difference persists into adulthood, with more than $60 \%(n=65 /$
108) of active females failing the TSPU compared to less than $10 \%(n=10 / 101)$ of active males. ${ }^{25}$ Collectively, this evidence suggests that poor performance on the TSPU develops early and persists into adulthood, even in healthy and active populations.

Several intervention programs designed to improve performance on the FMS ${ }^{\mathrm{TM}}$ exist in the literature. Nearly all are effective at improving composite scores on the FMS ${ }^{\text {тм }}$ within four to six weeks, in varied populations including firefighters, ${ }^{26,27}$ mixed martial arts athletes, ${ }^{28}$ professional football players, ${ }^{29}$ and Reserve Officer Training Corps (ROTC) cadets. ${ }^{30}$ However, there are several limitations that hinder a direct transfer of the results of these programs to the clinical treatment of trunk stability, as measured by the TSPU, in females. First, the populations studied are predominantly male. Only one study ${ }^{30}$ had greater than $4 \%$ of the sample represented by females, and three studies did not include any females. ${ }^{27-29}$ In a cluster randomized cohort, Basar et al. ${ }^{30}$ compared standardized group warm up exercises to individualized programs to determine effectiveness at improving FMS ${ }^{\mathrm{TM}}$ scores and Army Physical Fitness Test performance. While $41 \%$ of subjects were female $(n=18)$, no analysis based on gender was performed. Secondly, most studies that report improvement in FMS ${ }^{\text {тм }}$ scores after exercise intervention programs only report changes in the overall composite score, thus leaving it unclear as to which component screen of the FMS ${ }^{\mathrm{TM}}$ changed and led to the observed improvement.

Current recommendations for exercises to improve TSPU performance include single plane, anti-extension exercises. Such recommendations have excellent face validity, as antiextension exercises encourage maintenance of neutral lumbar spine positioning, particularly during anteriorly directed forces. This neutral lumbar spine position and control appear necessary to prevent the anterior pelvic tilt and trunk lag commonly observed in females while performing the TSPU (Figure 1). Despite the sound rationale, clinicians continue to observe suboptimal improvements in TSPU performance in females. It is likely that the exercise programming should be more comprehensive to see improved trunk stability as measured by the TSPU in this population.

Given the elevated incidence of LE injury, deficits in hip and trunk control, and high proportion of poor or failing scores on the TSPU, it is necessary to determine if trunk stability, measured by the TSPU, can be improved in active females. Development of a comprehensive program to improve performance on the TSPU may provide crucial information for clinicians struggling to improve trunk stability in their active female clients. Therefore, the primary purpose of this pilot study was to determine the effectiveness of a novel trunk stability exercise program in improving TSPU performance in a cohort of active female participants. It was hypothesized that $\geqslant 60 \%$ of participants would improve their TSPU scores following six weeks of intervention. The secondary purpose was to examine the program's effect on additional measures of movement quality, and trunk and dynamic stability. It was hypothesized that significant 


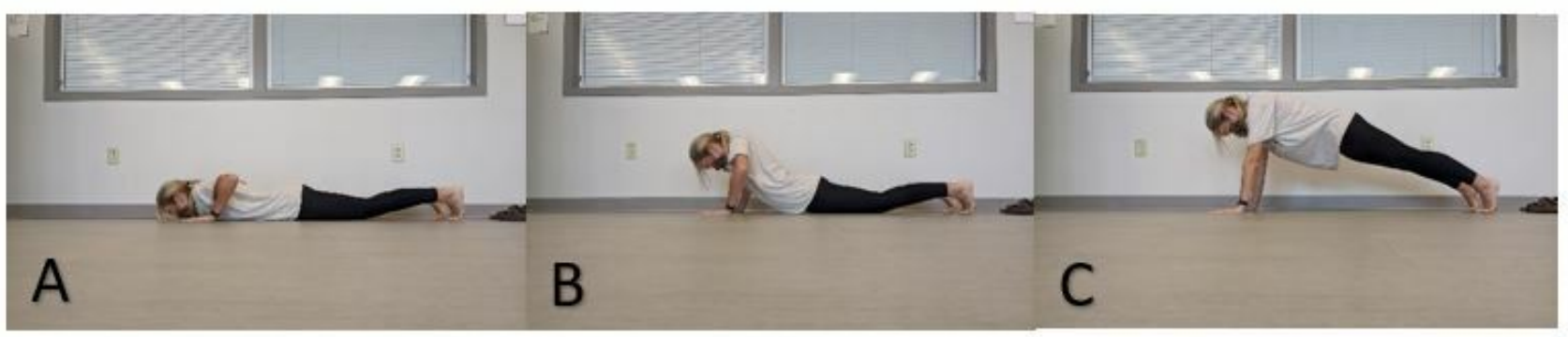

Figure 1. Illustration of a Trunk Stability Push Up (TSPU) failure. A. Start position for the TSPU. Hands are positioned under the shoulders, with thumbs at the height of the clavicles. B. Subjects were instructed to push up from the floor as a unit, keeping shoulders and hips level. C. End position for the TSPU.

improvements in these additional measures would be observed at posttest compared to baseline testing.

\section{METHODS}

Female participants, between the ages of 18 and 45, were recruited via flyer and e-mail from faculty and student clubs at the University of Evansville and the Stone Family Center for Health Sciences, which houses allied health programs from multiple universities. Female participants were eligible if they self-reported meeting physical activity guidelines by the American Heart Association ${ }^{31}$ for the last four consecutive weeks. Rolling recruitment of subjects occurred from October 2019-March 2020, with all participants belonging to either a fall or spring cohort. This study was approved by the Institutional Review Board at the University of Evansville.

Participants were screened for lumbar and shoulder pain by completing a prone press up and Yocum impingement test, respectively. If the subject reported pain with either test, she was excluded from the study. Additional exclusion criteria included: limitations of $>50 \%$ in shoulder mobility or active straight leg raise (based on American Academy of Orthopaedic Surgeons ${ }^{32}$ definitions), history of lumbar or shoulder surgery, history of anterior shoulder instability or recurrent shoulder dislocations, current pregnancy, and any non-musculoskeletal issue resulting in exercise restrictions from a healthcare provider.

Participants signed an informed consent then provided demographic information including age, height, weight, injury history, and current activity level. All data collection procedures were completed by three licensed physical therapists, two with board certifications (in orthopedics and sports) and one orthopedic physical therapy resident, with thirteen, eleven, and one years of experience with all data collection procedures respectively. Subjects were first assessed for generalized joint hypermobility, a factor that has impacted dynamic stability measures in other active female populations, ${ }^{33}$ using the Beighton score. The Beighton score is a common clinical assessment scored on a ninepoint scale, with operationally defined mobility assessments of the following (all movements performed bilaterally): extension of the $5^{\text {th }}$ metacarpophalangeal, elbow, and knee joints; forward bending; apposition of the thumb. Beighton scoring has substantial intrarater reliability (kappa $\left.=0.75^{34}\right)$ with a score of four or more representing hypermobility. 34,35

All participants completed the FMS ${ }^{\mathrm{TM}}$, which qualitatively screens fundamental movement patterns in people without known musculoskeletal pain. The FMS ${ }^{\text {тм }}$ has been described previously ${ }^{17}$ and studied extensively, demonstrating good reliability (ICC $=0.84-0.87$ ) among novice to experienced raters. ${ }^{36}$ The main outcome measure, the TSPU, is a subcomponent of the FMS ${ }^{\mathrm{TM}}$. All movement patterns for the FMS $^{\text {TM }}$ have established criteria and are scored on an ordinal scale from 0-3: 0 represents pain with the movement, 1 represents inability to perform the movement, 2 represents completion of the movement with compensations, and 3 represents completion of the movement without compensations. Because the purpose of this study was to improve TSPU performance, subjects scoring 2 or greater were considered to "pass" the TSPU component of the FMS ${ }^{\mathrm{TM}}$ and were therefore excluded. Subjects scoring a 1 were considered to "fail" the TSPU and could be included in the intervention.

All participants completed a breathing screen, which included a mini-questionnaire and a breath hold test using the protocol established by Kiesel et al. ${ }^{37}$ The breathing screen captures dysfunctional breathing, which has been linked to trunk musculature function. ${ }^{38,39}$ The mini-questionnaire has four items (Appendix 1) which are scored on an ordinal scale of $0-4(0=$ never, $1=$ rare, $2=$ sometimes, $3=$ often, $4=$ very often). Breath hold time following a normal exhalation (functional residual capacity) was then measured using a digital timer. A rating of 3-4 on any of the miniquestionnaire items in combination with a low breath hold time $(<25$ seconds) results in a sensitivity of 0.89 for identification of dysfunctional breathing in adults. ${ }^{37}$

Finally, the anterior reach of the Y-Balance Test-Lower Quarter (YBT-LQ) and the superolateral reach of the Y-Balance Test-Upper Quarter (YBT-UQ) were performed to capture a continuous measurement of dynamic trunk stability. These reaches were chosen because they are the most robustly studied directions, have excellent reliability, and are most associated with neuromuscular control deficits. ${ }^{40-42}$ In the anterior reach of the YBT-LQ, the subject must maintain single limb stance on the test kit, while using the opposite leg to push a slide box into the anterior direction. This is repeated on the opposite leg, with the maximum distance reached in three trials being used for analysis. In the super- 
Table 1. Results of paired t-tests for secondary, continuous outcomes.

\begin{tabular}{|c|c|c|c|c|c|}
\hline & \multicolumn{5}{|c|}{ Paired T-Test Results } \\
\hline & Test & $\mathrm{n}$ & Pretest $\bar{x}$ (SD) & Posttest $\bar{x}$ (SD) & p value \\
\hline & Breath Hold Test & 20 & $14.12(4.5)$ & $15.96(7.6)$ & 0.22 \\
\hline \multirow{2}{*}{ YBT-LQ } & Anterior Reach--Right & 12 & $58.6(6.4)$ & $58.6(7.5)$ & 0.99 \\
\hline & Anterior Reach--Left & 12 & $60.3(5.1)$ & $58.7(5.6)$ & 0.41 \\
\hline \multirow{2}{*}{ YBT-UQ } & Superior Lateral Reach--Right & 12 & $63.00(9.8)$ & $62.7(10.6)$ & 0.89 \\
\hline & Superior Lateral Reach--Left & 12 & $66.3(7.1)$ & $65.4(9.0)$ & 0.64 \\
\hline
\end{tabular}

YBT-LQ=Y-Balance Test, lower quarter. YBT-UQ=Y-Balance Test, upper quarter.

olateral reach of the YBT-UQ, the subject begins in a pushup position, then pushes the slide box in the superolateral direction relative to the supporting upper extremity. This is repeated on the opposite upper extremity, with the maximum distance reached in three trials being used for analysis.

Following data collection, subjects who failed the TSPU were instructed on the first of a three-part series of exercises. Instruction was provided by physical therapy students through verbal and physical demonstrations; written handouts of exercises were also provided to the participants. The exercise program was designed to improve recruitment of trunk musculature and the subject's overall control of movement using a neurodevelopmental approach. The first series of exercises included four movements, focused primarily on postural awareness and spinal mobility. Subjects returned at weeks two and four to learn new exercises. Exercises became progressively more challenging with each series. By the third series, subjects completed more dynamic, full-body movements, such as the Turkish get-up, a bear crawl, and an eccentric push-up from an elevated surface (Appendix 2). Throughout the intervention period, participants were asked to complete a daily home exercise journal to assess compliance, which was returned at the end of the study.

\section{STATISTICAL ANALYSIS}

All data were analyzed using SPSS statistical software (IBM SPSS Statistics, Version 26.0). Descriptive statistics were calculated for all subjects. The primary outcome variable was the proportion of treatment successes, defined as passing the TSPU test using previously established criteria from Cook et al. ${ }^{42}$ With a two-tailed alpha level of significance equal to $0.05,32$ subjects were needed in the intervention program to have $>80 \%$ power to detect the hypotheses described above based on a chi-square test. Secondary outcomes including the FMS ${ }^{\mathrm{TM}}$ and breathing screen, were evaluated using Wilcoxon signed ranks test. Changes in baseline YBT-LQ, YBT-UQ, and breath hold tests were ana- lyzed at posttest with paired t-tests.

\section{RESULTS}

Twenty-two females consented to participate in the study, however, two were excluded due to a history of shoulder instability. Therefore, twenty subjects participated in the study (Figure 2); mean age was 22.06 (1.8) years, mean height was 66.15 (2.9) inches, and mean weight was 143.50 (21.5) pounds. Due to the COVID-19 pandemic, only one subject in the spring cohort was able to perform posttests in person. Therefore, only tests that could be completed by visual assessment and required no equipment (breathing screen, breath hold test, and TSPU) were collected on the other eight subjects in the spring cohort. The planned secondary analyses were performed for all outcome measures using the remaining 12 subjects with completed posttest data.

At pretest, all subjects screened for inclusion in the study failed the TSPU. Beighton scores ranged from 0-9, with 10 subjects scoring 0 . The range of FMS $^{\mathrm{TM}}$ scores was 9-16, with a median score of 14 . A frequency count of breathing screen mini-questionnaire responses is available in Appendix 2. Sixty-five percent of subjects responded to at least one of the mini-questionnaire items as "often" or "very often". At pretest, $30 \%(n=6 / 20)$ of participants selected "often" or "very often" in response to the question "Do you notice yourself breathing through your mouth at night?" Mean breath hold time was 14.12 seconds (4.5).

At posttest, nine of the 20 subjects (45\%) passed the TSPU ( $\chi 2=1.876 ; \mathrm{p}=0.171$ ). The breathing screen question with the largest percentage of "often" or "very often" responses was "Do you feel tense?" at 25\%, though no significant differences were observed $(\mathrm{p}=0.06-0.77)$. No significant differences were observed in breath hold time [Mean 15.96 seconds (7.6); $\mathrm{p}=0.217]$. Aside from the TSPU ( $\mathrm{p}=0.013$ ), no significant differences were observed in remaining secondary analysis for the YBT-LQ or YBT-UQ ( $\mathrm{p}=0.56-0.89$; Table 1) or the FMS ${ }^{\mathrm{TM}}(\mathrm{p}=0.180-1.0$; see Figure 3$)$. 


\section{DISCUSSION}

Current research indicates that large proportions of active, healthy females are unable to complete the TSPU, a fundamental movement pattern, without compensations. This is the first study to explore interventions designed to improve TSPU performance in females. Although the COVID-19 pandemic resulted in poorer home exercise compliance and loss of posttest data points, $45 \%$ of females had passing TSPU scores at posttest. Additionally, this study had the second largest female representation in an $\mathrm{FMS}^{\mathrm{TM}}$ corrective exercise program with twelve subjects completing all FMS ${ }^{\mathrm{TM}}$ components compared to previous intervention studies which included four ${ }^{26}$ and eighteen ${ }^{30}$ females.

The primary goal of this study was to explore the effectiveness of a six-week trunk stability exercise program at improving the TSPU test. While the improvement observed in this study fell short of the hypothesis, $45 \%(n=9 / 20)$ represents a larger proportion of successful performance on the TSPU compared to other literature in female populations. Commonly utilized approaches for improving TSPU performance includes static exercises (ie planks), single plane movements, ${ }^{27,28,30}$ or strength training. ${ }^{27,43}$ While these studies have shown improvements in total FMS ${ }^{\mathrm{TM}}$ score, most of the subjects were males $27,28,43$ and multiplanar dynamic trunk stability are largely unaddressed. The intervention program utilized in the current study incorporated a combination of both anti-extension and anti-rotation exercises, progressing in postural demand, to train the trunk from a more comprehensive and functional perspective. Many participants demonstrated more coordinated movement between the upper body, trunk, and pelvis at posttest, however, they were only able to rise one to two inches from the floor, resulting in a failing score on the TSPU. Additionally, all subjects scored a 3 bilaterally on the shoulder mobility pattern, suggesting that upper quarter mobility restrictions are not present and, therefore, are unlikely to contribute to poor performance on the TSPU. Thus, additional contributing factors, such as upper body strength, need to be explored to create an effective program to improve TSPU performance in females.

Though the secondary purpose explored the program's impact on additional continuous outcome measures of trunk and dynamic stability, such as breath hold time and dynamic balance, this study was underpowered. Posttesting for the spring cohort was performed virtually for all but one subject due to the COVID-19 pandemic. These virtual follow-ups were not conducive to collection of several outcome measures, such as the YBT-LQ and YBT-UQ, and 6 of 7 of the FMS ${ }^{\mathrm{TM}}$ patterns, which led to a loss of several posttest data points; therefore, only 12 participants had completed all outcome measures for secondary analysis. Due to low power, no significant differences in these secondary outcome measures were observed.

One of the more interesting relationships observed was between participants with high Beighton scores and TSPU performance. Because systemic hypermobility impacts ligamentous integrity, poor global stability can be observed. ${ }^{44}$ However, a greater proportion of subjects with high $(\geqslant 4)$ Beighton scores passed the TSPU at posttest compared to subjects with low scores (0-3) (Figure 4). This is an encour-

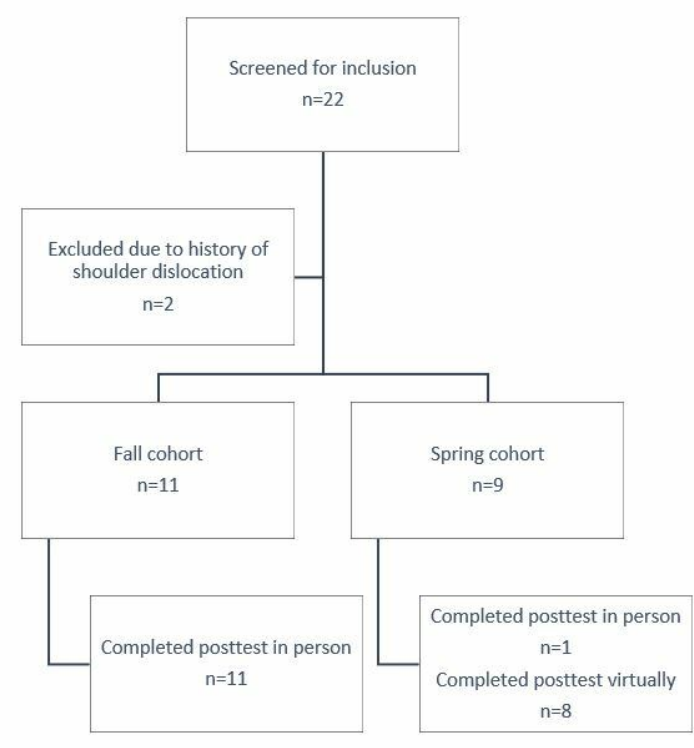

Figure 2. CONSORT flowchart.

aging finding, as it demonstrates that this population can still make progress in clinical stability outcomes despite global laxity.

\section{LIMITATIONS}

This study was impacted substantially by the COVID-19 pandemic. Forty percent $(n=8)$ of subjects in the spring cohort were unable to receive face-to-face instruction for the final exercise progression and were unable to attend in person posttest data collection. Only eight subjects returned exercises logs at posttest; zero were from the spring cohort. Anecdotally, the spring cohort subjects reported a failure to perform the corrective exercises after they were dismissed from campus. Therefore, compliance and follow up for the second cohort was poor, potentially limiting success with prescribed interventions. Additionally, the age range in this sample of active females was $20-25$ years old, though the target was 18-45. Thus, generalization to other populations and ages is limited.

\section{CONCLUSION}

The results of this study indicate that a multiplanar approach may be beneficial for improving trunk stability in active females, though additional contributing factors should be explored. Because males consistently outperform females on measures of trunk stability, even after intervention, there appears to be a need for a new approach to training trunk stability in female populations. This pilot study offers information regarding a novel program. 


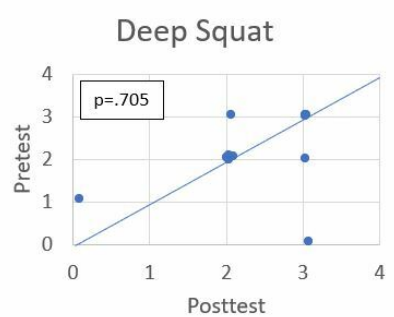

Shoulder Mobility, Right \& Left Combined

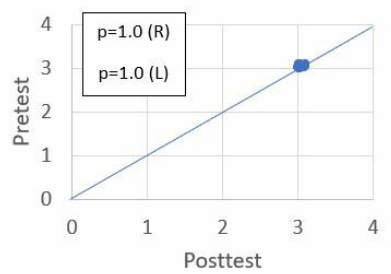

Hurdle Step, Right \& Left Combined

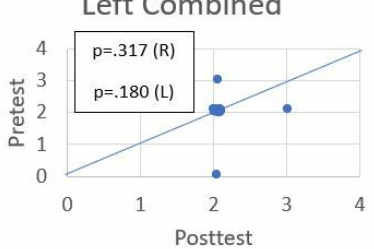

Active SLR, Right \& Left Combined

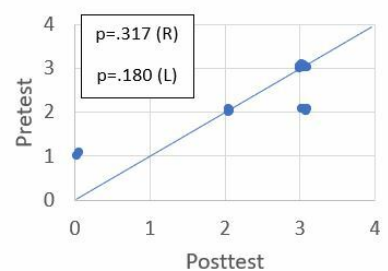

In-Line Lunge, Right \& Left Combined

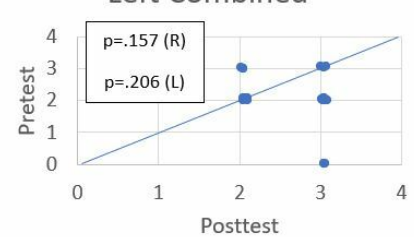

Trunk Stability Push Up

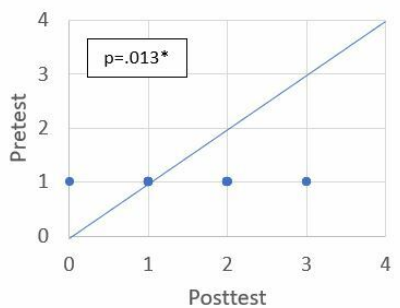

Rotary Stability, Right

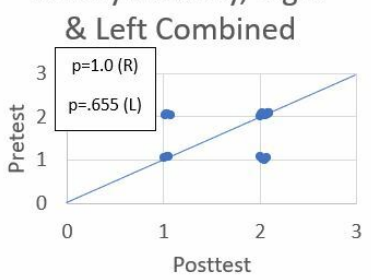

Figure 3. Comparison of pretest versus posttest performance on individual Functional Movement Screen ${ }^{\mathrm{TM}}$ component scores. Points falling above the line indicate a decrease in component score at posttest, while points below the line indicate improvement in scores at posttest. SLR=Straight Leg Raise. *=statistically significant

\section{CONFLICTS OF INTEREST}

The authors report no conflict of interest.

Submitted: January 13, 2021 CDT, Accepted: August 23, 2021 CDT

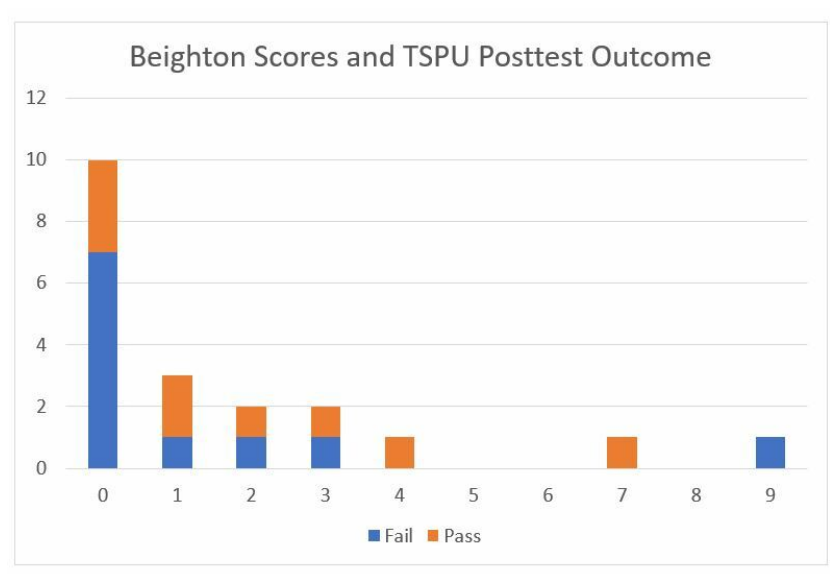

Figure 4. Frequency of Beighton scores and Trunk Stability Push Up (TSPU) performance. 


\section{REFERENCES}

1. Matzkin E, Garvey K. Sex differences in common sports-related injuries. NASN Sch Nurse. 2019;34(5):266-269. doi:10.1177/1942602x19840809

2. Lin CY, Casey E, Herman DC, Katz N, Tenforde AS. Sex differences in common sports injuries. $P M \& R$. 2018;10(10):1073-1082. doi:10.1016/j.pmrj.2018.03.0 $\underline{08}$

3. Stanley LE, Kerr ZY, Dompier TP, Padua DA. Sex differences in the incidence of anterior cruciate ligament, medial collateral ligament, and meniscal injuries in collegiate and high school sports: 2009-2010 through 2013-2014. Am J Sports Med. 2016;44(6):1565-1572. doi:10.1177/036354651663092 7

4. Changstrom BG, Brou L, Khodaee M, Braund C, Comstock RD. Epidemiology of stress fracture injuries among US high school athletes, 2005-2006 through 2012-2013. Am J Sports Med. 2015;43(1):26-33. doi:1 $\underline{0.1177 / 0363546514562739}$

5. Meucci RD, Fassa AG, Faria NMX. Prevalence of chronic low back pain: Systematic review. Rev Saúde Pública. 2015;49(0). doi:10.1590/s0034-8910.2015049 005874

6. CDC - Injury - WISQARS cost of injury module. htt ps://wisqars.cdc.gov:8443/costT/cost_Part1_Finished.j sp. Accessed September 11, 2019.

7. Ford KR, Myer GD, Schmitt LC, Uhl TL, Hewett TE. Preferential quadriceps activation in female athletes with incremental increases in landing intensity. $J$ Appl Biomech. 2011;27(3):215-222. doi:10.1123/jab.2 7.3.215

8. Hewett TE, Myer GD, Ford KR. Decrease in neuromuscular control about the knee with maturation in female athletes. J Bone Joint Surg Am. 2004;86(8):1601-1608. doi:10.2106/00004623-200408 $\underline{000-00001}$

9. Smith HC, Vacek P, Johnson RJ, et al. Risk factors for anterior cruciate ligament injury: A review of the literature - part 1: Neuromuscular and anatomic risk. Sports Health. 2012;4(1):69-78. doi:10.1177/19417381 $\underline{11428281}$

10. Brophy RH, Staples JR, Motley J, Blalock R, StegerMay K, Halstead M. Young females exhibit decreased coronal plane postural stability compared to young males. HSS J. 2016;12(1):26-31. doi:10.1007/s11420-0 15-9458-4
11. Leetun DT, Ireland ML, Willson JD, et al. Core stability measures as risk factors for lower extremity injury in athletes. Med Sci Sports Exerc. 2004;36(6):926-934.

12. Waldhelm A, Li L. Endurance tests are the most reliable core stability related measurements. J Sport Health Sci. 2012;1(2):121-128. doi:10.1016/i.jshs.201 $\underline{2.07 .007}$

13. McGill SM, Childs A, Liebenson C. Endurance times for low back stabilization exercises: Clinical targets for testing and training from a normal database. Arch Phys Med Rehabil. 1999;80(8):941-944. doi:10.1016/s0003-9993(99)90087-4

14. Abdallah AA, Mohamed NA, Hegazy MA. A comparative study of core musculature endurance and strength between soccer players with and without lower extremity sprain and strain injury. Int J Sports Phys Ther. 2019;14(4):525-536. doi:10.26603/ijspt201 $\underline{90525}$

15. O'Connor S, McCaffrey N, Whyte E, Moran K. The development and reliability of a simple field based screening tool to assess core stability in athletes. Phys Ther Sport. 2016;20(40-44):40-44. doi:10.1016/j.pts p.2015.12.003

16. Johnson CD, Whitehead PN, Pletcher ER, et al. The relationship of core strength and activation and performance on three functional movement screens. $J$ Strength Cond Res. 2018;32(4):1166-1173. doi:10.151 9/jsc.0000000000001943

17. Cook G. Movement: Functional Movement Systems: Screening, Assessment, Corrective Strategies. On Target Publications; 2010.

18. Mokha M, Sprague PA, Gatens DR. Predicting musculoskeletal injury in National Collegiate Athletic Association division II athletes from asymmetries and individual-test versus composite Functional Movement Screen scores. J Athl Train.

2016;51(4):276-282. doi:10.4085/1062-6050-51.2.07

19. Kiesel K, Plisky PJ, Voight ML. Can serious injury in professional football be predicted by a preseason Functional Movement Screen? N Am J Sports Phys Ther. 2007;2(3):147-158.

20. Bonazza NA, Smuin D, Onks CA, Silvis ML, Dhawan A. Reliability, validity, and injury predictive value of the Functional Movement Screen: A systematic review and Meta-analysis. Am J Sports Med. 2017;45(3):725-732. doi:10.1177/036354651664 1937 
21. Teyhen DS, Shaffer SW, Lorenson CL, et al. The Functional Movement Screen: A reliability study. J Orthop Sports Phys Ther. 2012;42(6):530-540. doi:10.2 519/jospt.2012.3838

22. Abraham A, Sannasi R, Nair R. Normative values for the Functional Movement ScreenTM in adolescent school aged children. Int J Sports Phys Ther. 2015;10(1):29-36.

23. Anderson BE, Neumann ML, Huxel Bliven KC. Functional Movement Screen differences between male and female secondary school athletes. J Strength Cond Res. 2015;29(4):1098-1106. doi:10.1519/jsc.0000 $\underline{000000000733}$

24. Chimera NJ, Smith CA, Warren M. Injury history, sex, and performance on the Functional Movement Screen and Y balance test. J Athl Train. 2015;50(5):475-485. doi:10.4085/1062-6050-49.6.02

25. Schneiders AG, Davidsson Å, Hörman E, et al. Functional Movement ScreenTM normative values in a young, active population. Int J Sports Phys Ther. $2011 ; 6(2)$.

26. Cowen VS. Functional fitness improvements after a worksite-based yoga initiative. J Bodyw Mov Ther. 2010;14(1):50-54. doi:10.1016/j.jbmt.2009.02.006

27. Frost DM, Beach TAC, Callaghan JP, McGill SM. Using the Functional Movement Screen ${ }^{\mathrm{TM}}$ to evaluate the effectiveness of training. I Strength Cond Res. 2012;26(6):1620-1630. doi:10.1519/jsc.0b013e318234 ec59

28. Bodden JG, Needham RA, Chockalingam N. The effect of an intervention program on functional movement screen test scores in mixed martial arts athletes. J Strength Cond Res. 2015;29(1):219-225. do $\mathrm{i}: 10.1519 /$ isc.0b013e3182a480bf

29. Kiesel K, Plisky P, Butler R. Functional movement test scores improve following a standardized offseason intervention program in professional football players. Scand J Med Sci Sports. 2011;21(2):287-292. $\underline{\mathrm{d}}$ oi:10.1111/i.1600-0838.2009.01038.x

30. Basar MJ, Stanek JM, Dodd DD, Begalle RL. The influence of corrective exercises on Functional Movement Screen and physical fitness performance in Army ROTC cadets. J Sport Rehabil. 2019;28(4):360-367. doi:10.1123/jsr.2018-0086

31. How much physical activity do you need? http s://www.heart.org/en/healthy-living/fitness/fitness-b asics/aha-recs-for-physical-activity-infographic. Accessed June 8, 2021.

32. Norkin CC, Joyce White D. Measurement Of Joint Motion: A Guide To Goniometry. F.A. Davis; 2016.
33. Ambegaonkar JP, Cortes N, Caswell SV, et al. Lower extremity hypermobility, but not core muscle endurance influences balance in female collegiate dancers. Int J Sports Phys Ther. 2016;11(2):220-229.

34. Remvig L, Jensen DV, Ward RC. Epidemiology of general joint hypermobility and basis for the proposed criteria for benign joint hypermobility syndrome: Review of the literature. J Rheumatol. 2007;34(4):640-647.

35. Kumar B, Lenert P. Joint hypermobility syndrome: Recognizing a commonly overlooked cause of chronic pain. Am J Med. 2017;130(6):640-647. doi:10.1016/i.a mimed.2017.02.013

36. Cuchna JW, Hoch MC, Hoch JM. The interrater and intrarater reliability of the functional movement screen: A systematic review with meta-analysis. Physical Therapy in Sport. 2016;19:57-65. doi:10.1016/ j.ptsp.2015.12.002

37. Kiesel K, Rhodes T, Mueller J, Waninger A, Butler R. Development of a screening protocol to identify individuals with dysfunctional breathing. Intl J Sports Phys Ther. 2017;12(5):774-786. doi:10.26603/ijspt201 $\underline{70774}$

38. Hodges PW, Sapsford R, Pengel LHM. Postural and respiratory functions of the pelvic floor muscles. Neurourol Urodyn. 2007;26(3):362-371. doi:10.1002/n au.20232

39. Whittaker JL. Ultrasound imaging of the lateral abdominal wall muscles in individuals with lumbopelvic pain and signs of concurrent hypocapnia. Man Ther. 2008;13(5):404-410. doi:10.10 16/j.math.2007.03.008

40. Plisky PJ, Gorman PP, Butler RJ, et al. The reliability of an instrumented device for measuring components of the star excursion balance test. $N \mathrm{Am} \mathrm{J}$ Sports Phys Ther. 2009;4(2):92-99.

41. Gorman PP, Butler RJ, Plisky PJ, Kiesel KB. Upper quarter Y balance test. J Strength Cond Res. 2012;26(11):3043-3048. doi:10.1519/isc.0b013e31824 $\underline{72 \mathrm{fdb}}$

42. Westrick RB, Miller JM, Carow SD, et al. Exploration of the Y-balance test for assessment of upper quarter closed kinetic chain performance. Int $J$ Sports Phys Ther. 2012;7(2):139-147.

43. Goss DL, Christopher GE, Faulk RT, et al. Functional training program bridges rehabilitation and return to duty. J Spec Oper Med. 2009;9(2):29-48. 
44. Yew KS, Kamps-Schmitt KA, Borge R.

Hypermobile Ehlers-Danlos syndrome and

hypermobility spectrum disorders. Am Fam Physician.

2021;103(8):481-492. 


\section{SUPPLEMENTARY MATERIALS}

\section{Appendix 1. Breathing screen mini-questionnaire and frequency of responses.}

Download: https://ijspt.scholasticahq.com/article/28055-the-effect-of-a-novel-training-program-to-improve-trunkstability-push-up-performance-in-active-females-a-pilot-study/attachment/70186.docx

\section{Appendix 2.}

Download: https://ijspt.scholasticahq.com/article/28055-the-effect-of-a-novel-training-program-to-improve-trunkstability-push-up-performance-in-active-females-a-pilot-study/attachment/70557.pdf 